\title{
Tingkat depresi dan jenis kelamin berhubungan dengan perilaku anti sosial pada pelajar SMA
}

\author{
Sari Riastiningsih ${ }^{1}$ Nuryani Sidarta ${ }^{2}$
}

\begin{abstract}
ABSTRAK
\section{LATAR BELAKANG}

Prevalensi penderita depresi pada usia remaja meningkat sangat tinggi dibandingkan dengan usia kanak-kanak dan dewasa. Prevalensi gangguan mental emosional pada penduduk berumur 15 tahun ke atas di Indonesia mencapai $6 \%$. Remaja rentan terkena depresi karena banyaknya proses adaptasi terhadap berbagai stressor kehidupan yang ada, bila tidak diawasi dapat menimbulkan gangguan perilaku anti sosial yang dapat menetap menjadi gangguan kepribadian antisosial pada saat dewasa. Studi ini dilakukan untuk menilai hubungan antara tingkat depresi dengan perilaku anti sosial pada pelajar SMA.
\end{abstract}

\section{METODE}

Studi ini merupakan penelitian analitik observasional dengan desain potong lintang yang dilakukan dari bulan Agustus hingga Desember 2017. Populasi penelitian adalah pelajar SMAN 6 Bogor dengan total sampel sebanyak 350 responden. Cara pengambilan sampel digunakan teknik Consecutive Non random sampling dan pengambilan data primer didapatkan dari pengisian kuesioner The Mansion Evaluation untuk menilai ada tidaknya perilaku anti sosial dan kuesioner Beck Depression Inventory-II guna mengukur tingkat depresi pada respondents. Selanjutnya data dianalisis dengan menggunakan tes Chi Square guna menilai hubungan antara tingkat depresi dengan munculnya perilaku antisosial.

\section{HASIL}

Dari 350 responden didapatkan 193 responden (55,1\%) yang mengalami depresi dari tingkat ringan sampai berat. Sebanyak 222 respoden $(63,4 \%)$ memiliki kecenderungan untuk berperilaku anti sosial dan lebih banyak didapatkan pada pelajar laki-laki. Hasil analisis menunjukkan adanya hubungan bermakna antara tingkat depresi dengan perilaku anti sosial dimana makin tinggi tingkat depresi maka makin besar kejadian perilaku anti sosial $(\mathrm{p}$ value $=0,000)$. Selain itu didapatkan pula bahwa jenis kelamin juga memiliki hubungan bermakna dengan munculnya perilaku anti sosial $(p$ value $=0,020)$.

\section{KESIMPULAN}

Terdapat hubungan antara tingkat depresi dan jenis kelamin dengan perilaku anti sosial pada pelajar SMA.

Kata kunci : depresi, anti sosial, pelajar
${ }^{1}$ Program Studi Kedokteran,

Fakultas Kedokteran, Universitas Trisakti

2 Departemen Anatomi, Fakultas Kedokteran, Universitas Trisakti

\section{Korespondensi:}

Nuryani Sidarta

Departemen Anatomi,

Fakultas Kedokteran,

Universitas Trisakti

Email:

nuryani_sidarta@trisakti.ac.id

J Biomed Kes 2018;1(1):3-9

DOI: 10.18051/JBiomedKes.2018.

v1.3-9

pISSN: 2621-539X / eISSN: 2621-5470

Artikel akses terbuka (open access) ini didistribusikan di bawah lisensi Creative Commons Attribution 4.0 International (CC-BY 4.0) 


\section{ABSTRACT}

\section{Level of depression and gender have correlation with anti social behaviour in senior high school student}

\section{BACKGROUND}

Recent data showed a significant increase in the prevalence of depression among adolescent compared to children and adults. Riskesdas 2013 revealed the prevalence of emotional-mental disorder in 15 years old civilians in Indonesia reached out $6,0 \%$. Adolescents are vulnerable to depression because of adaptation towards a lot of stressor in life. If they are not observed seriously, this case could evoke persistent anti-social behavior in the future. This study aims to determine the correlation between level of depression with anti-social behavior in senior high school students.

\section{METHODS}

A cross-sectional analytic observational study was conducted at SMAN 6 Bogor from August to December 2017. Three hundred fifty respondents were selected by using consecutive non random sampling technique. Respondents was asked to filled The Mansion Evaluation questionnaire to measure the indication of anti social behaviors and Beck Depression Inventory-II questionnaire to measure the level of depression. A Chi Square analysis was performed using statical program to measure the relation between level of depression and anti social behaviors in the respondents.

\section{RESULT}

Out of 350 respondents, these study showed that 193 respondents $(55,1 \%)$ were depressed and 222 respondents $(63,4 \%)$ tended to have anti-social behaviors. Study showed that male students had higher incidence of anti-social behaviors than female. Data analysis revealed a significant correlation between level of depression and anti-social behavior with $p$ value $=0,000(p<0,05)$ and a significant correlation between gender and anti-social behavior with $\mathrm{p}$ value $=0,020(\mathrm{p}<0,05)$.

\section{CONCLUSION}

This study revealed a correlation between level of depression and gender with anti-social behavior in high school students.

Keywords : depression, anti-social, student

\section{PENDAHULUAN}

Depresi merupakan suatu kondisi dimana terjadi gangguan fungsi manusia yang berkaitan dengan alam perasaan yang sedih dan gejala penyertanya, termasuk perubahan pada pola tidur dan nafsu makan, psikomotor, konsentrasi, anhedonia, kelelahan, rasa putus asa dan tidak berdaya serta bunuh diri. ${ }^{(1)}$ Survei World Mental Health yang dilakukan di 17 negara menemukan bahwa rata-rata sekitar 1 dari 20 orang dilaporkan mengalami episode depresi, yang terburuk depresi bisa menyebabkan bunuh diri. ${ }^{(2)}$ Riskesdas 2013 memaparkan prevalensi gangguan mental emosional pada penduduk berumur 15 tahun ke atas penduduk Indonesia mencapai 6,0\%. ${ }^{(3)}$ Dalam buku "Managemen Cemas dan Depresi, Hawari memaparkan bahwa Angka depresi berat lebih banyak ditemukan perempuan daripada laki-laki. ${ }^{(4)}$ Thapar dkk pada tahun 2012 menyimpulkan bahwa prevalensi depresi sepanjang hidup meningkat sesuai dengan prevalensi depresi sekitar 5\% pada awal masa remaja, pertambahan usia dimana didapatkan kemudian meningkat menjadi $20 \%$ pada akhir masa remaja dengan puncaknya terjadi pada usia 15-18 tahun. $^{(5)}$

Penelitian di Indonesia pada tahun 2008 oleh Damayanti dkk menyimpulkan bahwa remaja rentan terkena depresi karena banyaknya proses adaptasi terhadap berbagai stressor kehidupan yang ada. Apabila kondisi tersebuttidak diawasimakadapatmenimbulkan gangguan perilaku antisosial yang dapat menetap menjadi gangguan kepribadian anti sosial pada saat mereka dewasa. ${ }^{(6)}$ Berdasarkan data dari National Collaborating Centre for Mental Health di Inggris pada tahun 2010, menyatakan bahwa angguan psikososial yang umumnya terjadi pada remaja membuat remaja lebih mudah mengalami stress, depresi maupun gangguan psikososial lainnya dan remaja tersebut cenderung menyendiri, namun bila hal itu dibiarkan dapat menyebabkan gangguan depresi lanjut maupun perilaku anti sosial. ${ }^{(7)}$ Berdasarkan studi epidemiologi di beberapa negara yang dilakukan oleh 
Moral P pada tahun 2006 maka didapatkan bahwa angka kejadian perilaku anti sosial pada remaja di Indonesia ditemukan sekitar 5 juta penduduk atau 2,1\%, lebih sering ditemukan pada laki-laki dan umumnya ditemukan pada pemukiman dan lingkungan yang miskin dan timbul sebelum usia 15 tahun. Studi tersebut juga menyimpulkan bahwa orang dengan gangguan kepribadian antisosial (antisocial personality disorder) secara persisten melakukan penyimpangan dan pelanggaran terhadap hak-hak orang lain dan sering melanggar hukum. ${ }^{(8)}$ Burt dkk yang meneliti tentang perilaku anti sosial pada anak anak juga menyebutkan bahwa anakanak yang memiliki perilaku anti sosial akan cenderung mengabaikan norma dan konvensi sosial, impulsif, serta gagal dalam membina hubungan interpersonal dan pekerjaan. ${ }^{(9)}$

Berdasarkan uraian di atas, depresi dan gangguan perilaku anti sosial merupakan salah satu masalah kesehatan jiwa dan gangguan kepribadian yang harus diatasi di kalangan remaja maupun dewasa. Kondisi depresi dapat mengakibatkan penurunan produktivitas seseorang oleh karena perasaan emosi tidak stabil sehingga menimbulkan gangguanperilaku antisosial yang dapat meresahkan masyarakat bila tidak segera ditangani dan mendapat tindakan yang tepat. (10) Hal yang serupa juga didapatkan dari penelitian yang dilakukan Vassalo tahun 2011 pada remaja di Australia Hasil didapatkan bahwa pelajar yang berperilaku anti sosial cendeurng membuat mereka berperilaku kurang baik di lingkungannya. ${ }^{(11)}$

Tingginya depresi pada usia remaja di Indonesia serta dampak negatifnya pada kehidupan sehari-hari kemudian melatarbelakangi peneliti untuk menilai tingkat depresi pelajar sekolah menengah atas (SMA) serta hubungannya dengan munculnya perilaku anti sosial.

\section{METODE}

Penelitian ini menggunakan metode observasional analitik dengan desain penelitian cross sectional. Penelitian dilakukan pada 350 responden yaitu pelajar di SMAN 6 Bogor yang sedang duduk di kelas X dan XI. Alasan pemilihan SMAN 6 Bogor sebagai subjek penelitian adalah karena tingginya angka tawuran yang sering terjadi di lingkungan sekolah tersebut. Pelajar yang sedang dalam pengaruh obat psikotropika atau pelajar dengan gangguan psikiatri tidak dimasukkan ke dalam penelitian ini.

Pemilihan sampel dilakukan secara Consecutive Non random sampling dimana peneliti memberikan kuesioner ke seluruh responden yang memenuhi kriteria dan dilakukan sampai jumlah sampel terpenuhi. Instrumen yang digunakan untuk menilai tingkat depresi dan ada tidaknya perilaku anti sosial adalah dengan cara pengisian kuesioner oleh para responden. Kuesioner yang digunakan adalah The mansion evaluation dan Beck Depression Inventory-II yang keduanya telah tervalidasi untuk menilai ada tidaknya perilaku anti sosial serta tingkat depresi. ${ }^{(12-14)}$

Pada perhitungan nilai depresi maka setiap gejala dirangking dalam skala intensitas 1 sampai 4. Bila total nilai di bawah 9 maka responden tidak masuk dalam kriteria depresi. Namun bila total nilai 10-18 akan dimasukkan sebagai depresi ringan, 19-29 dimasukkan sebagai depresi sedang dan nilai total di atas 29 akan dimasukkan sebagai depresi berat. Hal yang sama juga berlaku untuk perhitungan nilai gejala perilaku anti sosial. Bila responden memberikan jawaban "ya" maka akan diberikan nilai 1 dan bila responden menjawab "tidak" maka nilai 0 akan diberikan. Responden yang mendapatkan total nilai di bawah 20 mengindikasikan tidak adanya perilaku anti sosial, namun bila total nilai 21 ke atas akan dikategorikan memiliki perilaku anti sosial.

Sebelum memulai pengisian kuesioner oleh responden maka seluruh responden dikumpulkan dalam satu ruangan dan peneliti memberikan arahan umum tentang tatacara pengisian kuesioner. Kemudian peneliti membagikan kuesioner langsung kepada responden, satu demi satu dan pengisian kuesioner dilakukan dengan didampingi oleh peneliti. Apabila terdapat pertanyaan yang kurang jelas maka responden dapat menanyakan langsung kepada peneliti. 
Masing-masing responden mengisi kuesioner di tempat duduknya dan tidak terdapat komunikasi antar responden. Data yang didapatkan adalah nilai dari hasil pengisian kedua kuesioner yang kemudian diolah dengan program statistik dengan tingkat kemaknaan sebesar 0,05 dan mengunakan uji Chi square.

\section{HASIL}

Tabel 1. Karateristik responden $(n=193)$

\begin{tabular}{lc}
\hline Karateristik & $\mathrm{N}$ \\
\hline Jenis Kelamin & 168 \\
Laki-laki & 182 \\
Perempuan & \\
Kategori Tingkat Depresi & 157 \\
Normal & 131 \\
Depresi Ringan & 52 \\
Depresi Sedang & 10 \\
Depresi Berat & \\
Kategori Perilaku Anti Sosial & 128 \\
Normal & 222 \\
Anti Sosial & \\
\hline
\end{tabular}

Berdasarkan tabel 1 di atas didapatkan bahwa $193(55,1 \%)$ responden memiliki kondisi deperesi dan 10 diantaranya berada dalam kondisi depresi berat. Prevalensi yang lebih tinggi didapatkan pada perilaku anti sosial dimana didapatkan lebih dari separuh total respoden $(63,4 \%)$ memiliki perilaku anti sosial.

Tabel 2. Hubungan Jenis kelamin dengan anti sosial $(\mathrm{n}=193)$

\begin{tabular}{lcccc}
\hline Jenis kelamin & Normal & $\begin{array}{c}\text { Anti } \\
\text { sosial }\end{array}$ & Total & $\mathrm{p}$ \\
\hline Laki-laki & 51 & 117 & 168 & $* 0,020$ \\
Perempuan & 77 & 105 & 182 & \\
\hline
\end{tabular}

* uji Chi square

Tabel 2 menunjukkan prevalensi jenis kelamin laki-laki yang mengalami perilaku anti sosial lebih tinggi dibanding perempuan dan terdapat hubungan jenis kelamin dan perilaku anti sosial menunjukan hubungan yang bermakna.
Tabel 3. Hubungan tingkat depresi dengan perilaku anti sosial $(n=193)$

\begin{tabular}{lcccc}
\hline Tingkat depresi & Normal & Anti sosial & Total & $\mathrm{p}$ \\
\hline $\begin{array}{l}\text { Minimal/ } \\
\text { normal }\end{array}$ & 103 & 54 & 157 & \\
Ringan & 21 & 110 & 131 & $* 0,000$ \\
Sedang & 4 & 48 & 52 & \\
Berat & 0 & 10 & 10 & \\
\hline
\end{tabular}

* uji Chi square

Tabel 3 menunjukkan bahwa dengan semakin meningkatkanya tingkat depresi maka semakin tinggi pula prevalensi munculnya perilaku anti sosial. Dari 10 orang responden yang memiliki depresi berat maka semua responden tersebut $(100 \%)$ memiliki perilaku anti sosial. Analisis hubungan tingkat depresi dan perilaku anti sosial menunjukan adanya hubungan yang bermakna.

\section{PEMBAHASAN}

Berdasarkan hasil penelitian yang didapatkan pada studi ini menunjukkan bahwa dari 350 pelajar yang diminta untuk mengisi kuesioner The Mansion Evaluation guna menilai ada tidaknya kecenderungan perilaku anti sosial pada para pelajar tersebut, didapatkan bahwa 222 pelajar $(63,4 \%)$ memiliki kecenderungan perilaku anti sosial. Prevalensi ini jauh lebih tinggi bila dibandingkan dengan data dari penelitian epidemiology yang dilakukan oleh Moral $\mathrm{P}$ pada tahun 2006 menunjukkan bahwa angka kejadian perilaku anti sosial pada remaja di Indonesia adalah sekitar 5 juta penduduk $(2,1 \%)$. Tingginya angka perilaku anti sosial pada lingkungan pelajar SMAN6 ini menjelaskan tingginya kejadian tawuran di lingkungan sekolah tersebut.

Hal lain yang juga dinilai dari studi ini adalah prevalensi dari tingkat depresi pada pelajar SMA tersebut. Studi ini mendapatkan bahwa lebih separuh $(55,1 \%))$ dari pelajar SMAN 6 Bogor memiliki kondisi depresi. Prevalensi ini sedikit lebih tinggi bila dibandingkan dengan data dari WHO yang menunjukkan bahwa 1 dari 20 orang dilaporkan mengalami episode depresi. Nilai ini juga lebih tinggi bila dibandingkan dengan 
data Riskesdas tahun 2013 yang menyatakan bahwa prevalensi gangguan mental emosional pada penduduk berusia 15 tahun ke atas adalah sekitar 6\%. Berdasarkan tingkat depresi maka didapatkan bahwa sebagian besar pelajar masih berada pada tingkat depresi ringan yaitu sebanyak 131 pelajar (68\%) diikuti oleh $52(27 \%)$ pelajar dengan depresi sedang dan 10 pelajar $(0.05 \%)$ yang mengalami depresi berat. Hasil studi ini serupa dengan studi yang dilakukan oleh Madyarini pada tahun 2014 pada pelajar SMA yang mendapatkan prevalensi depresi ringan adalah sebesar $83,6 \%$. $^{(15)}$

Melihat tingginya prevalensi anti sosial dan tingkat depresi maka dilakukan uji statistik guna melihat hubungan antara kedua variabel tersebut. Studi ini mendapatkan bahwa semakin tinggi tingkat depresi seorang pelajar maka semakin tinggi pula kecenderungan munculnya perilaku anti sosial. Uji statistik menunjukkan bahwa hubungan antara kedua variabel tersebut memiliki tingkat kepercayaan yang sangat bermakna. Hasil studi ini sejalan dengan penelitian yang dilakukan oleh Ritakallio dan teman-teman pada tahun 2010 pada para pelajar di Finlandia. Mereka melakukan penelitian guna melihat hubungan antara tingkat depresi dengan perilaku anti sosial. Studi mereka menekannya bahwa tingginya kejadian depresi dapat menyebabkan perilaku anti sosial dan remaja dengan kecenderungan anti sosial cenderung lebih menutup diri dari dukungan sosial.(16) Pada penelitian yang dilakukan di oleh Luee Horng,2010 ${ }^{(17)}$ pada pelajar di negara Taiwan utara disimpulkan tingginya angka anti sosial dikarenakan emosi remaja yang belum stabil dan hubungan antar anak dan orangtua yang kurang baik sehingga menyebabkan kecenderungan perilaku anti sosial pada pelajar tersebut. Berdasarkan data yang ada di Indonesia, hasil studi ini juga sesuai dengan penelitian yang dilakukan oleh Budi Setyawan dan teman-teman yang melakukan penelitian pada komunitas punker di Yogjakarta pada tahun 2015. (18) Hasil penelitian mereka menyimpulkan adanya hubungan antara depresi dengan kecenderungan perilaku anti sosial. Adanya depresi membuat para anggota komunitas punker menjadi lebih bersikap anti sosial dan berperilaku agresif.

Faktor lain yang juga dinilai dari studi ini adalah melihat hubungan antar jenis kelamin dengan munculnya perilaku anti sosial pada para pelajar SMA. Studi ini melibatkan pelajar laki-laki dan perempuan dengan proporsi pelajar laki-laki sebesar $48 \%$ dan pelajar perempuan sebanyak 52\%. Hasil studi menunjukkan bahwa prevalensi perilaku anti sosial pada laki-laki lebih tinggi dibandingkan dengan perempuan. Dari 158 pelajar laki-laki didapatkan 107 pelajar (68\%) yang memiliki perilaku anti sosial. Prevalensi ini sedikit lebih tinggi bila dibandingkan dengan pelajar perempuan yang memiliki angka prevalensi anti sosial sebesar 58\%. Penemuan ini sejalan dengan data yang dipublikasikan oleh Hawari dalam buku "Managemen cemas dan depresi" yang menyatakan bahwa laki-laki memiliki prevalensi lebih tinggi memiliki perilaku anti sosial. Berdasarkan hasil analisis bivariat yang terlihat pada table 3 didapatkan hasil $\mathrm{p}=0,020$ $(p<0,05)$ yang menunjukan bahwa terdapat hubungan yang bermakna antara jenis kelamin dan perilaku anti sosial. Hasil serupa juga didapatkan dari penelitian yang dilakukan oleh Baskoro dan teman-teman pada tahun 2010. Mereka melakukan penelitian pada 37 pelajar SMA di Sekolah Mardisiswa, Semarang. Hasil yang didapat menunjukkan adanya hubungan antara jenis kelamin, penelitian tersebut menjelaskan bahwa laki-laki lebih 2 kali beresiko cenderung berperilaku anti social dibandingkan perempuan. ${ }^{(19)}$ Penelitian di Iowa oleh Donald Black dan teman-teman pada tahun 2015 juga menyatakan bahwa lakilaki lebih banyak cenderung berperilaku anti sosial dan onset munculnya perilaku tersebut lebih dini bila dibandingakan dengan remaja perempuan. ${ }^{(20)}$

\section{Kekurangan penelitian}

Penelitian ini merupakan penelitian potong lintang sehingga hanya memberikan satu kali gambaran pada satu saat tertentu. Hal ini tentu saja kurang memberikan gambaran proses perkembangan kondisi mental yang dinilai (dalam hal ini adalah 
perilaku depresi dan perilaku anti sosial). Selain itu, instrument yang digunakan untuk menentukan ada tidaknya depresi dan perilaku antisosial hanya menggunakan kuesioner yang dinilai oleh responden sendiri. Peneliti belum menggabungkan data dari pemeriksaan psikiatri untuk lebih memberikan gambar tentang kedua kondisi tersebut di atas. Walaupun peneliti sudah berusaha untuk menghilangkan faktor perancu dalam penelitian ini melalui kriteria ekslusi, terdapat beberapa faktor perancu yang belum dapat dihilangkan sepenuhnya seperti kelainan psikiatri yang belum terdiagnosa, pola asuh maupun stressor eksternal ataupun lingkungan pergaualn di luar lingkungan sekolah.

\section{KESIMPULAN}

Berdasarkan hasil penelitian mengenai hubungan tingkat depresi dengan perilaku anti sosial pada pelajar SMAN 6 Bogor dapat disimpulkan bahwa:

1. Terdapat hubungan antara tingkat depresi dengan perilaku anti sosial pada pelajar SMAN 6 Bogor dan semakin tinggi tingkat depresi maka semakin tinggi pula prevalensi perilaku anti sosial

2. Terdapat hubungan antara jenis kelamin dengan perilaku anti sosial pada pelajar SMAN 6 Bogor

\section{SARAN}

Sebagai pelajar agar dapat lebih terbuka dan mendiskusikan masalah maupun hambatan bersosialisasi kepada orang terdekat di lingkungan sekolah maupun keluarga, sedangkan sebagai pengajar agar lebih memperhatikan pelajar yang sulit bersosialisasi diberi masukan dan bimbingan. Memberi bimbingan konseling bagi pelajar yang suka melanggar peraturan dan bukan hanya sekedar hukuman kepada pelajar yang melanggar.

Pada penelitian selanjutnya dapat dilakukan penelitian prospektif dengan durasi pengamatan yang lebih panjang sehingga lebih dapat menilai hubungan antara variabel. Untuk lebih menunjang konfirmasi ada tidaknya perilaku depresi serta perilaku anti sosial pada para responden maka dapat ditambahkan pemeriksaan psikiatri yang dilakukan oleh ahlinya. Lebih menambahkan lagi faktor eksklusi lainnya sehingga faktor perancu dapat lebih dihilangkan pada penelitian selanjutnya.

\section{DAFTAR REFERENSI}

1. Kaplan HI, Saddock, BJ Grebb, J.A. Sinopsis psikiatri: ilmu pengetahuan perilaku psikiatri klinis. Jakarta : Bina Rupa Aksara.2010. p. 527-30.

2. World Health Organization. Depression; 2011. Available from: http://www.who.int/ mental_health/management/depression/ who_paper_depression_wfmh_2012.pdf Accessed May,2017.

3. Riset Kesehatan Dasar; RISKESDAS. 2013. Available from : http://www.depkes. go.id. Accessd May, 2017.

4. Hawari D. Manajemen cemas dan depresi. Jakarta:Balai Penerbit Fakultas Kedokteran Universitas Indonesia;2011. p.112-8.

5. Thapar A, Collishaw S, Pine DS, Thapar AK. Depression in adolescence. J Lancet 2012;379: 1056-67 doi:10.1016/S01406736(11)60871-4.

6. Darmayanti N. Gender dan depresi pada remaja. Fakultas Psikologi Universitas Gadjah Mada;2008;35(2):164-180.

7. National Collaborating Centre for Mental Health. Antisocial personality disorder treatment management and prevention. The British psychological society.2010.p 17-20, available from: https://www.ncbi. nlm.nih.gov/pubmed/21834198 accessed May.2017

8. Moral P. The epidemiology of antisocial personality disorder. Statistics by country for anti- social personality disorder;2006. Available https://www.ncbi.nlm.nih.gov/ pubmedhealth/PMH0015230/ accessed May, 2017.

9. Burt S, Donnellan M, Lacono WG et al. Age-of-onset or behavioral sub-types? A Prospective comparison of two approaches 
to characterizing the heterogeneity within antisocial Behavior. Journal Abnormal Child Psychology. 2011;5(3): p. 633- 644. doi: 10.1007/s10802-011-9491-9

10. Tricia K, Neppl Rand D, Conger Laura, et al. Intergenerational continuity in parenting behavior: mediating pathways and child effects.010; 45(5). p 1251-56.

11. Vasallo S, Renda J, Edwards B. Bullying in early adolescence and its association with anti-social behaviour, criminality and violence 6 and 10 years later. Australian Institute of Family Studies. 2011 Apr;21(2):117-27. doi : 10.1080/15388220.2013.840643

12. Manson MP, Huba GJ. The Manson Evaluation Manual. Los Angeles: Journal of Consulting Psychology;1987;13(5) p-386 doi.10.1037/h0050169

13. Ginting $H$, Näring G, van der Veld WM, et al. Validating the beck depression inventory-II in Indonesia's general population and coronary heart disease patients. International Journal of Clinical and Health Psychology. 2013; 13: 235-42.

14. Sorayah. Uji Validitas Konstruk Beck Depression Inventory-II (BDI-II). Jurnal Pengukuran Psikologi dan Pendidikan Indonesia. Jakarta:Fakultas Psikologi UIN.2015;1(4). P.31-46

15. Madyarini P, Karini M, Karyanta M. Hubungan pola asuh otoriter orangtua dengan depresi padaremaja di SMAN 2 Purworejo. Jurnal Fakultas Psikologi. Universitas Sebelas Maret;2014;3(1):p.1-22

16. Ritakallio M, Luukkaala $T$, Marttunen $\mathrm{M}$, et al.Comorbidity between depression and antisocial behaviour in middle adolescence: 2010;7(3): p. 164-71. doi:10.3109/08039480903264911

17. Bee-HorngLue,Wen-ChiWu,Lee-LanYen. Expressed. emotion and its relationship to adolescent depression and antisocial behavior in northern Taiwan. Journal Formos Med Association.10;109(2) doi: 10.1016/S0929-6646(10)60033-2.

18. Setyawan B. Hubungan Depresi dengan Kecenderungan Perilaku Anti Sosial pada Remaja di Komunitas Punkerdi
Yogyakarta. Tesis. Yogyakarta Universitas Gadjah Mada;2015.p1-4.

19. Baskoro P, Fitrikasari A. Hubungan antara depresi dengan perilaku anti sosial remaja di sekolah. Semarang. Universitas Diponegoro;2010;p.1-17

20. Black DW, The Natural History of Asociation Personality Disorder., University of Lowa, Department of Psychiatry;2015; 60(7)p: 309-314, doi : $10.1177 / 070674371506000703$ 